\title{
International Ear Care Day - 3rd March
}

In 2012, the World Health Organization (WHO) released estimates which suggest that 360 million persons across the world live with disabling hearing loss. ${ }^{1}$ Amongst persons above 65 years of age, one out of three is reported to have hearing loss, ${ }^{2}$ yet less than 3 per cent of persons receive the hearing aids they require. ${ }^{3}$ Equally troublesome is chronic otitis media, which affects 65 to 330 million people across the world. ${ }^{4}$

Despite the fact that two-thirds of people with hearing loss live in developing countries, ${ }^{5}$ services for hearing care remain elusive where they are most needed. The number of ENT surgeons per million ranges from 0 to 4 in low-income countries, as compared with a range of 9 to 178 ENT surgeons per million individuals in high-income countries. ${ }^{6}$ In 18 countries of sub-Saharan Africa, there is an average of less than 1 ENT surgeon per 100000 persons. ${ }^{7}$ Moreover, the current global health priorities for developing countries have yet to pay attention to hearing loss. ${ }^{8}$ The overall low level of awareness about ear diseases and hearing loss at all levels within society adds to the growing burden. ${ }^{9}$

The World Health Assembly of 1995 passed a resolution drawing attention towards the growing problem and public health impact of hearing loss. This resolution urged the WHO member states to prepare national plans for the prevention and control of major causes of avoidable hearing loss. Since then, WHO has worked to develop a number of tools to assist the development and implementation of suitable strategies for ear and hearing care. The primary ear and hearing care training manuals, guidelines for hearing aids, and guiding principles for neonatal and infant hearing screening are key to the implementation of preventive and rehabilitative strategies. A number of organisations and agencies across the world have joined forces with WHO. The CBM (Christian Blind Mission), Hearing Conservation Council, International Federation of Otolaryngological Societies, International Society of Audiology, and American Academy of Otolaryngology-Head and Neck Surgery have formed a consortium to support the WHO programme for the prevention of deafness and hearing loss.

The focus of this programme is twofold. A key component is the provision of technical support for countries to develop programmes and plans for ear and hearing care integrated within primary healthcare systems. The WHO member states can seek assistance for the planning of programmes, as well as the development of implementation strategies and monitoring tools.

The other aspect of the programme addresses the need for advocacy with global agencies, countries and communities, to harness greater political and social commitment towards the prevention, identification and management of hearing loss.

The International Ear Care Day is an opportunity to undertake advocacy at all possible levels: global, regional, national and community. This day was the outcome of the Beijing Declaration made during the 1st International Conference on Prevention and Rehabilitation of Hearing Loss in 2007. The date ' 3 March' was selected because of the similarity of the figures ' 3.3 ' with the shape of our ears. The day is observed with a designated theme, decided by WHO in collaboration with its partners, collaborating centres and experts. The 'day' provides a unique opportunity to work together to draw the attention of media, policy-makers, administrators, health professionals and the general public towards the cause of hearing loss. Following a single theme helps to focus on one single aspect of ear and hearing care in a concerted manner. By observing this day, we can all help to create a global movement. This will compel others to give ear and hearing care the attention it deserves and to show persons with hearing loss their due respect.

In order to raise the profile of ear and hearing care on the global health agenda, all of us - ear and hearing care professionals, non-governmental organisations, collaborating centres, persons with hearing loss and their caregivers - must be a part of this movement. As members of the health profession, we dedicate ourselves every day to caring for our patients and their wellbeing. By devoting one day to the public health aspect of our chosen field, we can reach many more, and be a part of a worldwide effort to raise awareness and resources for ear and hearing care.

DR SHELLY CHADHA

Technical Officer, Prevention of Blindness and Deafness, WHO HQ, Geneva 


\section{References}

1 World Health Organization, MBD (Mortality and Burden of Diseases unit). Global Estimates of Hearing Loss. Geneva: WHO, http://www.who.int/pbd/deafness/estimates/en/, last accessed on 23 February 2014

2 Stevens G, Flaxman S, Brunskill E, Mascarenhas M, Mathers $\mathrm{CD}$, Finucane M. Global and regional hearing impairment prevalence: an analysis of 42 studies in 29 countries. Eur J Public Health (Dec 24) 2011;1-7

3 World Health Organization. World Report on Disability. Geneva: WHO, 2011;102

4 World Health Organization. Chronic Suppurative Otitis Media: Burden of Illness and Management Options. Geneva: WHO, 2004

5 Olusanya BO, Newton VE. Global burden of childhood hearing impairment and disease control priorities for developing countries. Lancet 2007;369:1314-17. Erratum in: Lancet 2007; 369:1860. http://www.who.int/entity/pbd/publications / Chronicsuppurativeotitis_media.pdf, last accessed on 23 February 2014

6 Goulios H, Patuzzi R. Education and practice of audiology internationally. In: McPherson B, Brouillette R, eds. Audiology in Developing Countries. New York: Nova Science Publishers, 2008;75-105

7 Fagan J, Jacobs M. Survey of ENT services in Africa: need for a comprehensive intervention. Glob Health Action 2009;2: 10.3402 /gha.v2i0.1932

8 Olusanya BO. Addressing the global neglect of childhood hearing impairment in developing countries. PLoS Med 2007;4:e74

9 World Health Organization. Report of the Informal Working Group on Prevention of Deafness and Hearing Impairment Programme Planning, Geneva, 18-21 June 1991. Geneva: WHO, 1991 